\title{
Developing World ENT: a global responsibility
}

\author{
J J FAGAN \\ Division of Otorhinolaryngology, Faculty of Health Sciences, University of Cape Town, South Africa
}

\begin{abstract}
There exists a tremendous opportunity for otolaryngologists from developed countries to make a substantial contribution beyond their daily clinical practice, through involvement in teaching and training in the developing world. This article sets out the challenges presented by ENT practice within the developing world, and discusses ways in which these challenges can be addressed.
\end{abstract}

Key words: Developing World; ENT; Head and neck cancer; Otolaryngology; Africa; Open access

\section{Introduction}

More than 50 per cent of the world's population resides in developing world countries (Figure 1). The developing world accounts for 80 per cent of the world's 278 million people with bilateral conductive hearing loss, yet only one in 40 people who would benefit from hearing aids has one. ${ }^{1}$ The developing world also harbours the majority of cancer patients, and predictions indicate that by 2030 it will account for 70 per cent of newly diagnosed cancers; however, it accounts for only 5 per cent of global cancer spending. ${ }^{2}$

It is apparent from the above data that there exists a tremendous opportunity for otolaryngologists from developed countries to make a substantial contribution beyond their daily clinical practice, by supporting otolaryngology services in the developing world.

\section{Status of developing world ENT services}

Although Africa as a continent possibly represents the worst case scenario, there are many parts of the world where ENT services are virtually non-existent. In 2009, Fagan and Jacobs conducted an e-mail-based survey to assess the availability of ENT, audiology and speech therapy services and training facilities in 18 sub-Saharan African countries. ${ }^{3}$ They calculated the ratio of ENT surgeons per 100000 population for each country, and compared this with the same ratio for the UK, as shown in Figure 2. Malawi had only one ENT surgeon for its entire 12 million people, while nine of the 18 countries assessed had 10 or fewer ENT surgeons. The 18 countries together had a deficit of 4669 ENT surgeons, based on the UK ENT surgeon ratio. There is little reason to suspect that these figures have improved since this study was published.
Fagan and Jacobs' survey of ENT services in 18 sub-Saharan African countries had other striking findings. ${ }^{3}$ Only half the countries polled had their own ENT training programmes. The majority of patients did not have access to even the most basic otological surgical procedures, such as myringotomy with grommet insertion and tympanoplasty. Mastoid surgery for mastoiditis was not available in four countries, and it was quite possible for patients to die from treatable ear infections. Operating microscopes, otology drills and modern imaging equipment were not available in many countries, and in some countries mastoidectomy was still performed with a hammer and gouge. Only South Africa had a (small) cochlear implant programme. Audiology services were not available in many of the assessed countries. There was a deficit of 20406 audiologists needed to match UK service ratios, for the 18 countries as a whole. Hearing aids were not dispensed in seven countries, and were only poorly available in a further seven. Screening for hearing loss was not available in the majority of the countries. There was a deficit of 82541 speech therapists needed to match UK service ratios, for the 18 countries as a whole. Even the most basic head and neck oncological surgery (e.g. total laryngectomy and neck dissection, and parotid surgery) was not performed in many of the countries. Finally, radiation therapy was either unavailable or poorly available in 13 of the 18 countries.

Another study reported that radiotherapy facilities were available in only 23 of Africa's 53 countries. ${ }^{4}$ In countries that did have radiotherapy, equipment was often out-dated and unreliable, and waiting lists were very long. 

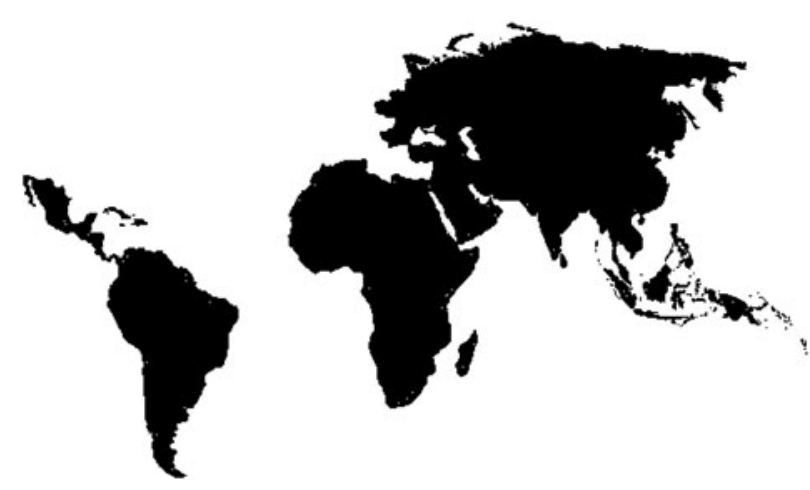

FIG. 1

Map of the developing world.

\section{Challenges facing developing world ENT}

Developing world ENT services are hampered by economic constraints, meagre health budgets, poor infrastructure (including unreliable electricity supply) and a shortage of trained medical staff. In addition, ENT service funding has to compete with the budgetary demands of life-threatening infectious diseases such as tuberculosis (TB) and human immunodeficiency virus infection (HIV). Consequently, the way in which ENT is practised in developing countries differs markedly from the high-technology, high-cost practices of the developed world.
In addition, ENT surgeons in the developing world are faced with a different disease spectrum. For example, both HIV and TB have numerous ENT manifestations. Harris and Fagan found that sensorineural hearing loss (SNHL) occurred in 57 per cent of patients with multidrug-resistant TB after three months' aminoglycoside therapy; in those who were also being treated for HIV, SNHL occurred in 70 per cent (Harris and Fagan, unpublished data). The HIV and associated TB pandemics are therefore creating a new deaf community in developing world countries, the rehabilitation of which requires ENT surgeons and audiologists.

Farmer et al. have alerted the international community to the 'cancer tsunami' that the developing world faces. ${ }^{2}$ The incidence of cancer in developing world countries is growing because of communicable disease control improvements with resultant increased life expectancy, changing social habits associated with affluence, and HIV. Farmer et al. have also reported a marked disparity in treatment outcomes for patients treated in developing versus developed world countries. ${ }^{2}$ They have also found an association between cancer fatality rates and national income: the cancer case fatality rate in low income countries is 75 per cent, as opposed to 45 per cent in high income countries. $^{2}$

The shortage of medical staff in developing world countries is a major limiting factor for effective

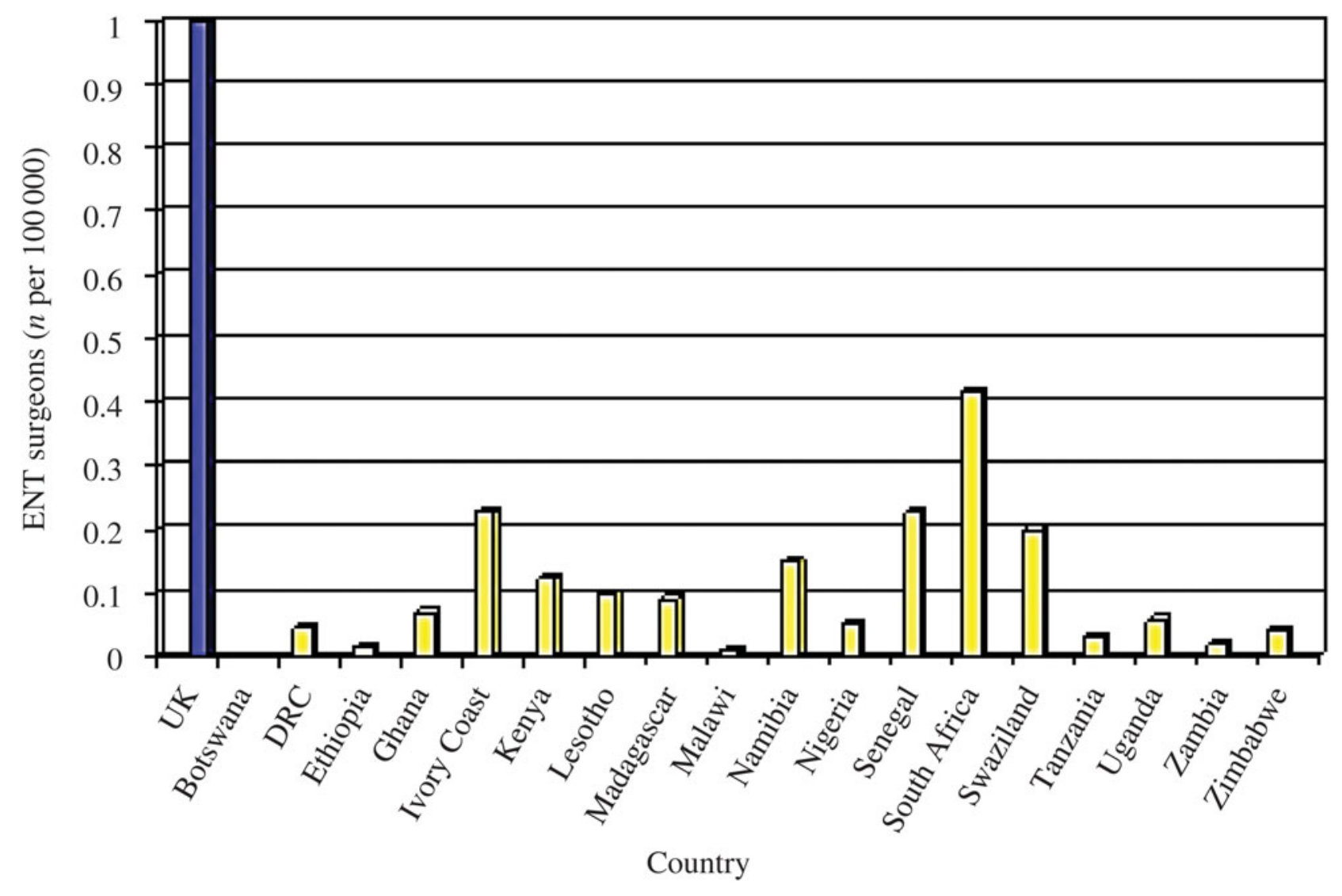

FIG. 2

The ratio of ENT surgeons per 100000 population for 18 sub-Saharan African countries and the UK. Published with permission. ${ }^{3}$ DRC $=$ Democratic Republic of Congo. 
delivery of healthcare. This shortage is very much apparent in the ENT arena, as reported by Fagan and Jacobs. $^{3}$ The recruitment of ENT surgeons is limited by a lack of training opportunities. Retention is hindered by an inability to compete with developed countries and non-government organisations, in terms of opportunities for career development, remuneration, working conditions and sociopolitical benefits. Health systems in sub-Saharan African countries have been severely compromised by migration of health professionals. Meanwhile, healthcare in English-speaking countries is reliant upon international medical graduates. This is reflected in the percentage of foreigntrained doctors who make up the total medical work force in the UK (28 per cent), Australia (27 per cent), the USA (25 per cent) and Canada (23 per cent). ${ }^{5} \mathrm{~A}$ large percentage of these foreign-trained doctors trained in low income countries $(75$ per cent in the UK, 40 per cent in Australia, 60 per cent in the USA and 43 per cent in Canada). ${ }^{5}$

\section{How can the global ENT community contribute?}

Despite the challenges outlined above, there are a number of ways in which the global ENT community can provide substantial assistance to advance ENT practice in developing world countries.

\section{Teaching and training}

The numbers and quality of developing world ENT surgeons, audiologists and speech therapists can only be increased by investing in teaching and training, and by improving staff retention. A new training programme could theoretically be established in any given developing world country in as little as five years, by training a cohort of ENT surgeons in developed countries who would then form the nucleus of a training centre. The quality of trainers could further be enhanced through additional fellowship programmes and by providing ongoing support through 'twinning' with developed world institutions.

\section{Medical migration}

Developed countries should train more of their own doctors, so as not to depend on international medical graduates from poor countries.

\section{Access to medical literature}

The developing world accounts for more than 50 per cent of the world's mobile phone users, and many poor countries have invested in fast internet connectivity. The ENT community should promote free, open access to ENT medical journals and textbooks.

\section{Appropriate technology}

Researchers should focus not only on high-cost technology but also on technology and techniques appropriate and transferable to a developing world setting, such as mobile phone based audiological screening for TB patients receiving ototoxic drugs.

\section{Non-government organisations}

Non-government organisations have invested heavily in combating infectious diseases such as malaria, TB and HIV. However, such investment does not reflect the burden of disease of poor countries, and there has been little investment in non-communicable conditions such as hearing loss. ${ }^{6}$ There is also evidence that the involvement of non-government organisations may skew health priorities, and that governments may direct tax revenue away from health. Non-government organisations should guard against aggravating medical staffing shortages by recruiting doctors who would otherwise have served in state health facilities. There has been a call for non-government organisations to 'invest in health systems and research capacity in low-income countries, leaving a sustainable footprint of [their] commitment'. 6 Ear, nose and throat surgeons and organisations need to lobby non-government organisations to invest in the treatment of ENT-related non-communicable diseases.

- Developing countries hold more than 50 per cent of the world's population

- Many such countries have no ENT services, despite ENT conditions being common

- ENT services are hampered by economic constraints, poor infrastructure and failure to retain trained staff

- Huge opportunities exist for partnerships between ENT providers from developed and developing countries

- The ENT community must lobby governments and the World Health Organization to raise awareness and develop initiatives

\section{Role of medical missions}

Medical missions such as ear camps fill an important niche in countries and regions where there is little prospect of ENT services being developed. However, ENT surgeons should guard against providing such services in countries and regions which are able to develop their own services; in such cases, the emphasis should be on assisting to establish and support local ENT training facilities.

\section{Conclusion}

Advancing ENT services in the developing world should be a priority for the global ENT community. This will require the involvement of ENT surgeons 
from developed countries in teaching, training, appropriate research, and lobbying governments, nongovernment organisations and the World Health Organization. However, it will also require a commitment from ENT colleagues in the developing world to remain within their own countries and to establish and strengthen their own training programmes, in order to facilitate assistance from developed world colleagues.

\section{References}

1 World Health Organization, Deafness and hearing impairment. In: http://www.who.int/features/factfiles/deafness/01_en.html [1 January 2012]

2 Farmer P, Frenk J, Knaul FM, Shulman LN, Alleyne G, Armstrong $\mathrm{L}$ et al. Expansion of cancer care and control in countries of low and middle income: a call to action. Lancet 2010;376:1186-93

3 Fagan JJ, Jacobs M. Survey of ENT services in Africa: need for a comprehensive intervention. Global Health Action 2009;2:e1-7
4 Sitas F, Parkin DM, Chirenje M, Stein L, Abratt R, Wabinga H. Part II: Cancer in indigenous Africans - causes and control. Lancet Oncol 2008;9:786-95

5 Mullan F. The metrics of the physician brain drain. N Engl J Med 2005;353:1810-18

6 Anonymous. What has the Gates Foundation done for global health? Lancet 2009;373:1577

Address for correspondence:

Professor J J Fagan,

Division of Otorhinolaryngology,

University of Cape Town,

H53 OMB, Groote Schuur Hospital, Observatory,

Cape Town 7925, South Africa

Fax: +27214488875

E-mail: johannes.fagan@uct.ac.za

Professor J J Fagan takes responsibility for the integrity of the content of the paper

Competing interests: None declared 